\title{
AMENDMENTS
}

\section{Publisher Correction: Metal halide perovskites: Perovskite transistors clean up their act}

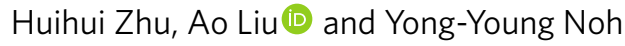

Correction to: Nature Electronics https://doi.org/10.1038/s41928-020-00470-z, published online 19 October 2020.

In the version of this News \& Views article originally published, the 'Competing interests' statement was missing, and should have read "The authors declare no competing interests."; this has now been added to all versions of the News \& Views article.

Published online: 27 October 2020

https://doi.org/10.1038/s41928-020-00503-7

(C) Springer Nature Limited 2020 